\title{
Produção de serapilheira de duas fisionomias do domínio Cerrado, Gurupi, Tocantins
}

\section{Leaflitter production in two Cerrado types, Gurupi, state Tocantins}

\author{
Paulo Ricardo Teixeira ${ }^{1}$, Rômullo Quirino de Souza Ferreira ${ }^{2}$, Marilia Oliveira Camargo ${ }^{3}$, Rubens Ribeiro da Silva ${ }^{4}$, Priscila \\ Bezerra de Souza ${ }^{5}$
}

Resumo: Objetivou-se verificar a produção de serapilheira de duas fisionomias do domínio Cerrado, sendo uma fisionomia de cerrado sensu stricto (s.s) e outra de mata ciliar, ambas as áreas estão localizadas na Fazenda Experimental da Universidade Federal do Tocantins, Campus de Gurupi-TO. Foram instalados aleatoriamente em cada uma das fisionomias estudadas dez coletores de 1 x $1 \mathrm{~m}$, os quais foram monitorados mensalmente durante o período maio de 2012 a abril de 2013 . A produção média de serapilheira total mostrou variação apenas no mês de outubro de 2012 e fevereiro de 2013 com uma produção anual de $1829,31 \mathrm{~kg} \mathrm{ha}^{-1}$ na fisionomia de mata ciliar e de $1349,01 \mathrm{~kg} \mathrm{ha}^{-1}$ na fisionomia de cerrado s.s. A fração mais representativa da serapilheira total encontrada nas duas fisionomias estudadas foi composta por folhas que perfazem $63,6 \%$ do total de material depositado nos coletores seguido pelas frações material lenhoso, flor e propágulo respectivamente.

Palavras-chave: Avaliação sazonal, serapilheira acumulada, cerrado sensu stricto, mata ciliar.

\begin{abstract}
The objective was to verify the leaflitter production of the two Cerrado types, one being stricto sensu Cerrado (s.s) and other riparian forests, both areas are located at the Experimental Farm of the Federal University of Tocantins, Campus of Gurupi-TO. Ten collectors of 1 x $1 \mathrm{~m}$ were randomly installed in each of the studied areas, which were monitored monthly during the period of May 2012 to April 2013. The mean litter production showed variation only in the month of October 2012 and February 2013 with an annual output of $1829.31 \mathrm{~kg} \mathrm{ha}^{-1}$ in the riparian physiognomy and $1349.01 \mathrm{~kg}$ ha ${ }^{-1}$ in the s.s. cerrado. The most representative fraction of Total litter found in the two physiognomies studied consisted of leaves making up $63.6 \%$ of the total material deposited in the traps followed by the timber fraction, flower and propagules respectively.
\end{abstract}

Key words: Seasonal evaluation, accumulated leaflitter, Cerrado domain.

\footnotetext{
*Autor para correspondência

Recebido para publicação em 02/06/2016; aprovado em 15/11/2016

${ }^{1}$ Mestrando em Ciências Florestais e Ambientais, Universidade Federal do Tocantins, Gurupi; paulo.engflorestal@hotmail.com.

${ }^{2}$ Mestre em Ciências Florestais e Ambientais, Universidade Federal do Tocantins, romulo_forest@uft.edu.br

${ }^{3}$ Mestre em Ciências Florestais e Ambientais, Universidade Federal do Tocantins, lilakamargo@ hotmail.com

${ }^{4}$ Professor Dr. do Curso de Pós-Graduação em Produção Vegetal, Universidade Federal do Tocantins, rrs2002@uft.edu.br

${ }^{5}$ Professora Dra. do Programa de Pós-Graduação em Ciências Florestais e Ambientais, Universidade Federal do Tocantins, priscilauft@uft.edu.br
} 


\section{INTRODUÇÃO}

O Brasil possui a maior área de Cerrado do Mundo, sendo o segundo maior bioma brasileiro com 2 milhões de $\mathrm{Km}^{2}$ de domínio nas terras altas do Brasil Central (MATOS, 2013) o mesmo apresenta uma vegetação com fitofisionomias bastante variadas em toda a sua extensão.

O bioma Cerrado comporta formações florestais, savânicas e campestres, com 11 tipos fitofisionômicos. As formações florestais do bioma são floresta ciliar, floresta de galeria, floresta seca e cerradão. As savânicas são cerrado sensu stricto, parque de cerrado, palmeiral e vereda. As formações campestres são campo sujo, campo limpo e campo rupestre (RIBEIRO; WALTER, 2008).

$\mathrm{Na}$ última década, o crescente interesse da ciência quanto ao funcionamento dos ecossistemas florestais naturais brasileiros, observado nas inúmeras pesquisas realizadas, possui a finalidade de subsidiar e orientar ações futuras de restauração, conservação e manejo sustentável destes locais (LONGHI et. al., 2011).

Longhi et. al., (2011) afirmam que para manejar qualquer formação florestal de maneira adequada é fundamental que se tenha conhecimento básico de estrutura e dinâmica das populações, suas relações e funções ecológicas, produtividade primária, entre outros. Uma das causas do manejo inadequado de formação florestal é o desconhecimento dos fatores que sustentam a alta produção de biomassa e, ainda, concomitantemente, que conservam a fertilidade do solo. Nesse contexto, o conhecimento sobre a produção da serapilheira e a ciclagem de nutrientes é primordial para um melhor entendimento da dinâmica nutricional no ecossistema, uma vez que, para a liberação de nutrientes pela serapilheira depositada é considerada o meio mais importante de transferência de nutrientes da vegetação para o solo (CALDEIRA et. al., 2008; LONGHI et. al., 2011).

As florestas tropicais apresentam produção contínua de serapilheira no decorrer do ano, sendo que as quantidades produzidas nas diferentes épocas dependem do tipo de vegetação considerada e de sua resposta às variações sazonais (GIÁCOMO et. al., 2012). Fatores como luz, temperatura, umidade do solo e disponibilidade de nutrientes estão sujeitos a alterações em decorrência da quantidade de serapilheira depositada, afetando, consequentemente, a germinação e o estabelecimento de plântulas (CARREIRA et. al., 2006).

De acordo com Calvi et. al., (2009), temperaturas elevadas, maior duração do período de luz e maior quantidade de insolação constituem os fatores climáticos mais relevantes para a produção da serapilheira. Os autores acrescentam que, de maneira geral, a serapilheira é composta de $60 \%$ a $80 \%$ de folhas, $1 \%$ a $15 \%$ de ramos e $1 \%$ a $25 \%$ de casca. Diferentes ecossistemas florestais depositam diferentes quantidades de serapilheira que também podem apresentar variações na proporção de frações constituintes. Para Carreira et. al., (2006), essas diferenças advêm principalmente do ciclo biológico e das condições climáticas.

Deste modo, afirma-se que o tipo de vegetação e as condições ambientais são fatores determinantes da quantidade e qualidade do material que cai no solo, determinando a heterogeneidade e a taxa de decomposição do material depositado na superfície do solo (SILVA et. al., 2012).

Portanto, o objetivo desse trabalho foi quantificar a produção de serapilheira ao longo de um ano, nas suas diferentes frações e fisionomias, sendo uma fisionomia de cerrado sensu stricto e outra de mata ciliar, Gurupi - TO, com vistas a oferecer informações valiosas para o manejo e a conservação do Cerrado.

\section{MATERIAL E MÉTODOS}

\section{Descrição da área de estudo}

$\mathrm{O}$ estudo foi realizado em duas fisionomias do domínio Cerrado, sendo uma fisionomia de cerrado sensu stricto (s.s) que se caracteriza por ter uma cobertura arbórea variando entre 5 e $70 \%$ sem formação de dossel. Possui arvores baixas, tortuosas, com cascas espessas e folhas geralmente coriáceas e pilosas. A luz solar alcança a superfície do solo onde se desenvolve exuberante comunidade herbácea com alguns arbustos (SILVA-JUNIOR, 2012). E outra fisionomia de mata ciliar que se caracteriza por ser comunidades ribeirinhas, decíduas ou semidecíduas com 50 a $90 \%$ de cobertura, associada aos maiores cursos de água. Sua composição florística difere daquela em matas de galeria (Silva-JUNIOR, 2012).

As áreas estudadas possuem 138 hectares de extensão total e estão localizadas na Fazenda Experimental da Universidade Federal do Tocantins, Campus de Gurupi - TO. O solo da área de estudo é caracterizado como Latossolo vermelho-amarelo distrófico (IBGE, 2007). Está localizada em uma altitude média de $280 \mathrm{~m}$, sob as coordenadas $11^{\circ} 46^{\prime} 25^{\prime \prime} \mathrm{S}$ e $49^{\circ} 02^{\prime} 54^{\prime \prime} \mathrm{W}$.

O clima da região segundo Köppen é do tipo AW, definido como tropical úmido com estação chuvosa no verão e seca no inverno. Os dados de precipitação pluviométrica utilizados na pesquisa foram obtidos da Estação Agrometeorológica da Universidade Federal do Tocantins, Campus de Gurupi - TO, compreendendo um período de um ano, de maio de 2012 a abril de 2013. A precipitação registrada durante o período estudado foi de $1064 \mathrm{~mm}$ e temperatura média ao longo do ano entre $24,2^{\circ} \mathrm{C}$ e $28,6^{\circ} \mathrm{C}$. De junho a agosto de 2012 ocorreu um período mais seco, coincidente com as temperaturas mais baixas, típico das regiões do domínio Cerrado (RONDON, 2006). Os dados de precipitação e temperatura do período de maio de 2012 a abril de 2013 da área estudada estão representados na (Figura 1). 
Figura 1. Temperatura e precipitação registrada no período de maio de 2012 a abril de 2013 das duas fisionomias estudadas, Fazenda Experimental da Universidade Federal do Tocantins, Campus de Gurupi - TO.

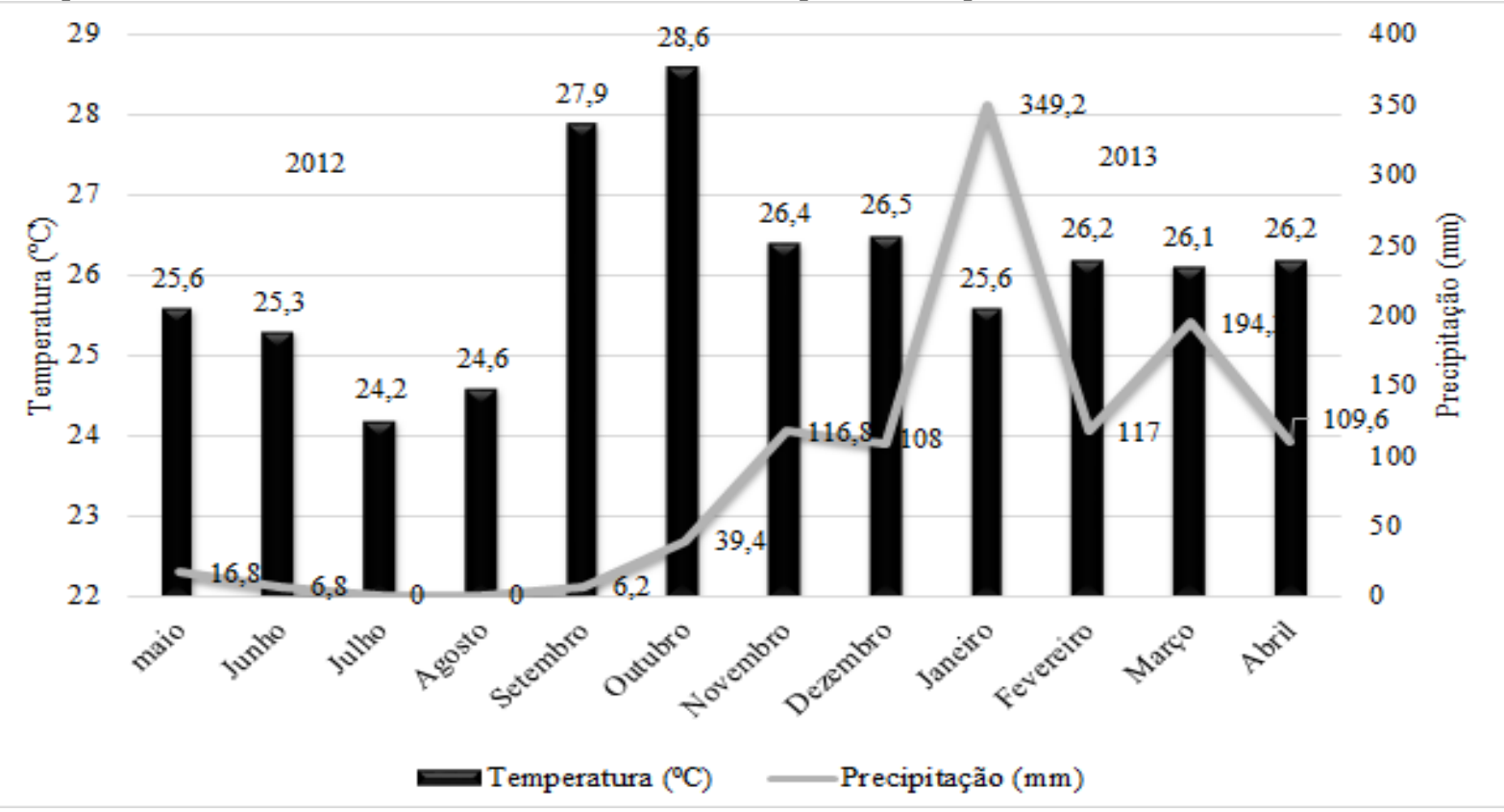

\section{Produção de serapilheira}

Foram instalados aleatoriamente em cada uma das fisionomias dez coletores de $1 \times 1 \mathrm{~m}$, com fundo de tela tipo sombrite $50 \%$ e profundidade de $0,10 \mathrm{~m}$. Os coletores foram sustentados por estacas com $0,30 \mathrm{~m}$ de altura do solo. O material vegetal depositado nos coletores foi retirado mensalmente, durante o período de maio de 2012 a abril de 2013 (TEIXEIRA et. al., 2016).

Dessa forma o material coletado foi acondicionado em sacos plásticos, etiquetados e conduzidos ao laboratório de Ecologia da UFT, onde foi seco à sombra e triado nas seguintes frações: folha, flor, propágulo e material lenhoso. Após a triagem, o material foi acondicionado em sacos de papel, etiquetados e levados à estufa com circulação de ar a $65^{\circ} \mathrm{C}$, por 48 horas, para secagem. Para obtenção dos valores de massa seca de cada fração da serapilheira foi utilizado uma balança analítica, com precisão de duas casas decimais (TEIXEIRA et. al., 2016).

\section{Análise estatística}

Com os dados obtidos nos coletores de cada fisionomia, foi calculado para cada coleta, as médias da serapilheira total e de suas frações.

Os dados foram submetidos a análises de variância com aplicação do teste F. As comparações entre as médias dos tratamentos das duas fisionomias foram feitas pelo uso do teste de Scott-Knott a 5\% de probabilidade utilizando o aplicativo computacional SISVAR (FERREIRA, 2008).

\section{RESULTADOS E DISCUSSÃO}

A produção média de serapilheira total entre as duas fisionomias mostrou variação significativa apenas no mês de outubro de 2012 e fevereiro de 2013 sendo que a fisionomia de mata ciliar apresentou maior deposição de serapilheira total nesses dois meses. Nos demais meses a produção média entre as fisionomias mostrou-se estatisticamente semelhantes (Figura 2).

A produção mensal de serapilheira na fisionomia mata ciliar variou de 51,6 a 267,3 kg ha-1, resultando numa produção anual de $1829,31 \mathrm{~kg}$ ha- 1 . Na área de cerrado sensu stricto a produção de serapilheira variou de 20,9 a $308,2 \mathrm{~kg}$ ha-1, registrando uma produção anual de $1349,01 \mathrm{~kg}$ ha- 1 . Dados estes que corroboram com Silva et. al., (2007) que atribui essa diferença ao cerrado sensu stricto ser uma vegetação semi-aberta, ou seja, com árvores espaçadas e pequenas além de ter pouca biomassa por unidade de área em relação às fisionomias florestais.

A maior produção de serapilheira na fisionomia de cerrado sensu stricto foi registrada no período da seca, fato este que pode ser explicado devido a produção de serapilheira seguir um padrão climatobotânico, ou seja, as espécies existentes no Cerrado são adaptadas ao clima ameno nos meses de inverno, onde a produção de serapilheira é maior, por grande parte das espécies perderem suas folhas neste período (árvores caducifólias) (PERUCELLI; ANTONELI, 2010). Segundo Silva et. al., (2007) e Maman et. al., (2007), a ocorrência de maior produção de serapilheira no período seco é influenciada principalmente pelo estresse hídrico podendo ser uma resposta da vegetação que com a derrubada de folhas reduziria a perda de água por transpiração. Estudos de produção de serapilheira realizados por (CIANCIARUSO et. al., 2006; GIÁCOMO et. al., 2012; MAMAN et. al., 2007; SCORIZAL; PIÑA-RODRIGUES, 2014; SIQUEIRA et. al., 2016; SILVA et. al., 2007), também observaram máxima produção de serapilheira no período de seca. Enquanto que na fisionomia de mata ciliar a produção de serapilheira oscilou ao longo do período estudado. Verifica-se que os valores encontrados condizem com aqueles registrados na literatura (PERUCELLI; ANTONELI, 2010) o que diferencia são as características da vegetação (Figura 2). 
Figura 2. Produção mensal de serapilheira total, registrada nas duas fisionomias estudadas, Fazenda Experimental da Universidade Federal do Tocantins, Campus de Gurupi - TO, no período de maio de 2012 a abril de 2013.

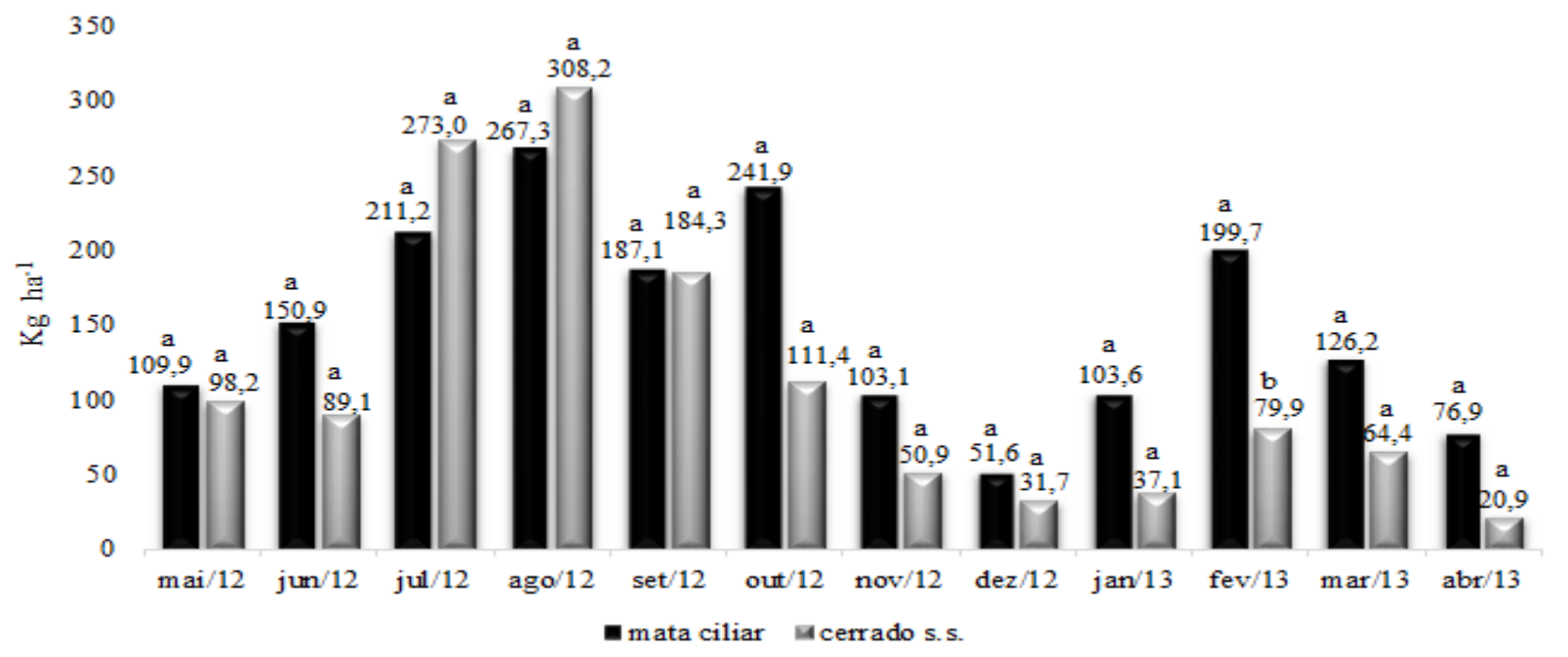

Letras iguais nas barras indicam igualdade significativa $(\mathrm{p}<0,05)$.

Os ecossistemas de florestas tropicais, via de regra, apresentam produção contínua de serapilheira no decorrer do ano, tendo a quantidade produzida nas diferentes épocas sido dependente do tipo de vegetação considerada (GIÁCOMO et. al., 2012) e das variações climáticas.

Quando analisado as frações separadas de cada mês para as duas fisionomias a produção mensal de serapilheira total mostrou-se bastante variável.

Nos meses de maio a outubro de 2012 em ambas as fisionomias a fração folha apresentou maiores valores de deposição de serapilheira quando comparadas com material lenhoso. Já no mês de novembro de 2012 a produção da fração folhas se destacou das demais frações analisadas onde as mesmas não diferiram estatisticamente.

Segundo Silva et. al., (2007) as folhas representam o compartimento mais importante na maioria dos estudos de produção de serapilheira em florestas tropicais. Essa fração depende principalmente das espécies, da estrutura do local e da idade das árvores, pois está em constante produtividade, por causa das trocas resultantes de altas taxas fotossintéticas, diferentes fenologias entre as espécies locais e pelas respostas mais rápidas às alterações ambientais (BARRETO et. al., 2007).

Entretanto, no período de maio a outubro de 2012 a fração flor e propágulo apresentaram quantidades bem inferiores as demais frações, além de não apresentar diferenças estatisticamente.

Entre os meses de dezembro de 2012 a janeiro 2013 todas as frações analisadas (material lenhoso, propágulo, flor e folhas), apresentaram valores estatisticamente semelhantes. Entretanto no mês de fevereiro de 2013 a fração flor contribuiu com baixo valor de serapilheira total. Nos meses de março e abril de 2013 as frações folha e material lenhoso mostraram-se semelhantes apresentando maior produção de serapilheira total. O restante dos meses houve uma variação pequena entre os valores de deposição (Tabela 1).

Tabela 1 - Produção de serapilheira total separado por frações folha, flor, propágulo e material lenhoso, registrada no período de maio de 2012 a abril de 2013, nas duas fisionomias estudadas, Fazenda Experimental da Universidade Federal do Tocantins, Campus de Gurupi - TO

\begin{tabular}{ccccc}
\hline \multicolumn{5}{c}{ Frações da serapilheira $\left(\mathrm{kg} \mathrm{ha}^{-1}\right)$} \\
\hline MESES & Folha & Flor & Propágulo & Mat. Lenhoso \\
\hline Maio/12 & $259,2 \mathrm{Ca}$ & $0,06 \mathrm{Ac}$ & $2,24 \mathrm{Ac}$ & $154,86 \mathrm{Ab}$ \\
Junho/12 & $307,14 \mathrm{Ca}$ & $0,71 \mathrm{Ac}$ & $9,19 \mathrm{Ac}$ & $162,95 \mathrm{Ab}$ \\
Julho/12 & $596,09 \mathrm{Ba}$ & $59,28 \mathrm{Ac}$ & $74 \mathrm{Ac}$ & $239 \mathrm{Ab}$ \\
Agosto/12 & $927,32 \mathrm{Aa}$ & $5,23 \mathrm{Ac}$ & $19,35 \mathrm{Ac}$ & $198,94 \mathrm{Ab}$ \\
Setembro/12 & $585,45 \mathrm{Ba}$ & $9,9 \mathrm{Ac}$ & $18,01 \mathrm{Ac}$ & $129,5 \mathrm{Ab}$ \\
Outubro/12 & $497,15 \mathrm{Ba}$ & $37,61 \mathrm{Ac}$ & $24,18 \mathrm{Ac}$ & $147,73 \mathrm{Ab}$ \\
Novembro/12 & $181,84 \mathrm{Da}$ & $23,79 \mathrm{Ab}$ & $18,7 \mathrm{Ab}$ & $83,6 \mathrm{Bb}$ \\
Dezembro/12 & $83,5 \mathrm{Da}$ & $2,93 \mathrm{Aa}$ & $20,45 \mathrm{Aa}$ & $59,51 \mathrm{Ba}$ \\
Janeiro/13 & $113,59 \mathrm{Da}$ & $1,5 \mathrm{Aa}$ & $80,17 \mathrm{Aa}$ & $86,09 \mathrm{Ba}$ \\
Fevereiro/13 & $184,41 \mathrm{Da}$ & $14,89 \mathrm{Ab}$ & $150,04 \mathrm{Aa}$ & $209,71 \mathrm{Aa}$ \\
Março/13 & $184,15 \mathrm{Da}$ & $4,84 \mathrm{Ab}$ & $24,97 \mathrm{Ab}$ & $167,28 \mathrm{Aa}$ \\
Abril/13 & $127,62 \mathrm{Da}$ & $0 \mathrm{Ab}$ & $61,47 \mathrm{Ab}$ & 61,47
\end{tabular}

Letras iguais minúsculas nas linhas indicam igualdade significativa das frações e letras iguais maiúsculas nas colunas indicam igualdade dos meses (p<0,05).

A maior deposição de folha foi registrada no período de maio a outubro de 2012, estação seca (Tabela 1 e Figura 1). Dados esses que corroboram com Silva et al., (2007) onde afirma que o aumento na queda de folhas no período da seca no domínio Cerrado, ocorre nos meses de baixa precipitação e o brotamento das folhas, a floração e a frutificação ocorrem no início e durante a estação de chuva, podendo ser influenciada por fatores ambientais variáveis como 
hidroperiodicidade e radiação solar (SILVA et al., 2007). Por conseguinte, Caldeira et. al., (2007) afirmaram que as folhas da serapilheira são responsáveis pelo retorno da maior quantidade de nutrientes ao solo, pois são depositadas grandes quantidades ao longo das estações do ano.

A deposição de flor e propágulo ao longo do ano não diferiu significativamente (Tabela 1). Enquanto que a fração material lenhoso teve uma maior produção de serapilheira no período de maio a outubro de 2012 e nos meses de fevereiro e março de 2013, o restante dos meses houve uma variação pequena entre os valores de deposição dados estes que corroboram onde afirma que as deposições de material lenhoso podem ser explicadas devido à incidência de ventos no local (SILVA et al., 2007).

\section{CONCLUSÕES}

A produção de serapilheira nas áreas de estudo mostrouse sazonal, com a maior queda de serapilheira na fisionomia cerrado sensu stricto ocorrendo durante a estação seca e a menor deposição durante a estação chuvosa. A maior produção anual de serapilheira ocorreu na fisionomia mata ciliar, entretanto, mostrou-se variável.

A fração foliar representou dois terços do total da serapilheira, nas duas fisionomias estudadas, enquanto que as frações flores e frutos apresentaram menor deposição durante o período de estudo.

\section{REFERÊNCIAS}

BARRETO, L.; ARZABE, C.; LIMA, Y. C. C. Herpeto fauna da região de Balsas. In Cerrado Norte do Brasil - North Cerrado of Brazil (L. Barreto, ed.). USEB, Pelotas, p. 221229, 2007.

CALDEIRA, M. V. W.; MARQUES, R; SOARES, R. V.; BALBINOT, R. Quantificação de serapilheira e de nutrientes - Floresta Ombrófila Mista Montana - Paraná. Revista Acadêmica, Curitiba, v. 5, n. 2, p. 101-116, 2007.

CALDEIRA, M. V. W.; VITORINO, M. D.; SCHAADT, S. S.; MORAES, E.; BALBINOT, R. Quantificação de serapilheira e de nutrientes em uma Floresta Ombrófila Densa. Semina: Ciências Agrárias, Londrina, v.29, n.1, p.5368, 2008.

CALVI, G. P.; PEREIRA, M. G.; JÚNIOR, A. E. Produção de serapilheira e aporte de nutrientes em areas de floresta atlântica em Santa Maria de Jetibá, ES. Ciência Florestal, Santa Maria, v. 19, n. 2, p. 131-138, 2009.

CARREIRA, R. C.; RONDON, J. N.; ZAIDAN, L. B. P. Produção de serapilheira em uma área de cerrado de Mogi Guaçu, SP. In: Curso de Capacitação de monitores e educadores, São Paulo. Anais ... São Paulo: Instituto de Botânica - IBt. 2006. p. 11.

CIANCIARUSO, M. V.; PIRES, J. S. R.; DELITTI, W. B. C.; SILVA, É. F. L. P. DA. Produção de serapilheira e decomposição do material foliar em um cerradão na Estação Ecológica de Jataí, município de Luiz Antônio, SP, Brasil. Acta Botânica Brasílica, Belo Horizonte, v. 20, n.1, p. 49-59, 2006.
FERREIRA, D. F. SISVAR: um programa para análises e ensino de estatística. Revista Symposium, Lavras, v. 6, p. 3641, 2008.

GIÁCOMO, R. G.; PEREIRA, M. G.; MACHADO, D. L. Aporte e decomposição de serapilheira em áreas de cerradão e mata mesofítica na estação ecológica de Pirapitinga - MG. Ciência Florestal, Santa Maria, v. 22, n. 4, p. 669-680, 2012.

IBGE - Instituto Brasileiro de Geografia e Estatística. Mapa exploratório de solos do estado do Tocantins. Pedologia, $2007 . \quad$ Disponível em: <ftp://geoftp.ibge.gov.br/informacoes_ambientais/pedologia/ mapas/unidades_da_federacao/to_pedologia.pdf>. Acesso em: 24 de nov. 2016.

JUNIOR, M. C. DA S. 100 ÁRVORES DO CERRADO SENTIDO RESTRITO - GUIA DE CAMPO. 1.ed. Brasília: Rede de Sementes do Cerrado, 2012. 360p.

LONGHI, R. V.; LONGHI, S. J.; CHAMI, L. B.; WATZLAWICK, L. F.; EBLING, A. A. Produção de serapilheira e retorno de macronutrientes em três grupos florísticos de uma floresta ombrófila mista, RS. Ciência Florestal, Santa Maria, v. 21, n. 4, p. 699-710, 2011.

MAMAN, A. P, DE; SILVA, C. J. DA; SGUAREZI, E. DE M.; BLEICH, M. E. Produção e acúmulo de serapilheira e decomposição foliar em mata de galeria e cerradão no sudoeste de Mato Grosso. Revista de Ciências AgroAmbientais, Alta Floresta, v.5, n.1, p.71- 84, 2007.

MATOS, W. H. Florística e fitossociologia em área de cerrado localizada ao extremo norte do planalto divisor Araguaia-Tocantins. In: SIMPEEX 2013 (Simpósio de Ensino, Pesquisa e Extensão) e $7^{\circ}$ Seminário de Iniciação Cientifica e Tecnológica, 2013, Goiânia. Anais ... Goiânia: Instituto Federal do Goiás. 2013. p. 9.

PERUCELLI, M.; ANTONELI, V. Produção de serrapilheira em uma floresta ombrófila mista sob o domínio do sistema de faxinal; estudo de caso do faxinal de papanduva de baixoprudentópolis - pr. XVI ENCONTRO NACIONAL DOS GEOGRAFOS. Porto Alegre, 2010. Anais... Porto Alegre: AGB, 2010, 11p.

RIBEIRO, J. F; WALTER, B. M. T. As principais fitofisionomias do Bioma Cerrado. In.: SANO, S. M; ALMEIDA, S. P; RIBEIRO, J. F. Ecologia e flora. Brasília: EMBRAPA, 2008. v. 1, p. 152-212.

RONDON, J.N. Autoecologia de Bauhiniaholophylla Steud. (Leguminosae - Cesalpinoide) na Reserva Biológica e Estação Experimental de Mogi Guaçu, SP. Tese de Doutorado, Universidade Estadual de Campinas, São Paulo, 2006, 76p.

SCORIZA, R. N.; PIÑA-RODRIGUES, F. C. M. Influência da precipitação e temperatura do ar na produção de serapilheira em trecho de floresta estacional em Sorocaba, SP. Floresta, Curitiba, v. 44, n. 4, p. 687 - 696, 2014. 
SILVA, F. L; ESCRIBANO, M. T; ALONSO, J. J. P; RIVAS-GONZALO, J. C; SANTOS-BUELGA, C. Anthocyanins pigments in strawberry. LWT, v. 40, n. 2, p. 374-382, 2007.

SILVA, C. J. DA; SANCHES, L.; BLEICH, M. E.; LOBO, F. DE A.; NOGUEIRA, J. DE S. Produção de serrapilheira no Cerrado e Floresta de Transição Amazônia-Cerrado do Centro-Oeste Brasileiro. Acta Amazonica, Manaus, v. 37, n. 4, p. $543-548,2007$.

SILVA, A. D. DA; JUNIOR, R. C. DE O.; TANABE, C. S.; MARTINS, I. C. T. Influência da precipitação e temperatura do ar na produção de liteira na Floresta Nacional do Tapajós, Belterra - PA. In: XII Salão de Pesquisa e Iniciação Cientifica do CEULS/ULBRA e Conexão de saberes pela pesquisa, 2007, Santarém. Anais ... Santarém: Centro Universitário Luterano de Santarém, CEULS/ULBRA. 2012. p. 52.

SIQUEIRA, T. M.; PINHEIRO, M. H. O.; SILVA. D. G. DA; FRANCO, T. M. Influências climáticas na produção de serapilheira em um cerradão em Prata - MG. Revista Biotemas, Florianópolis, v. 29 n. 2, p. 7-15, 2016.

TEIXEIRA, P. R.; FERREIRA, R. Q. DE S.; CAMARGO, M. O.; SOUZA, P. B. DE; TAVARES, R. DE C. Variação temporal de nutrientes $\mathrm{N}$ P K na serapilheira de duas fisionomias do domínio cerrado, Gurupi - TO. Revista Verde de Agroecologia e Desenvolvimento Sustentável, Pombal, v. 11 , n. 3, p. 39-46, 2016. 